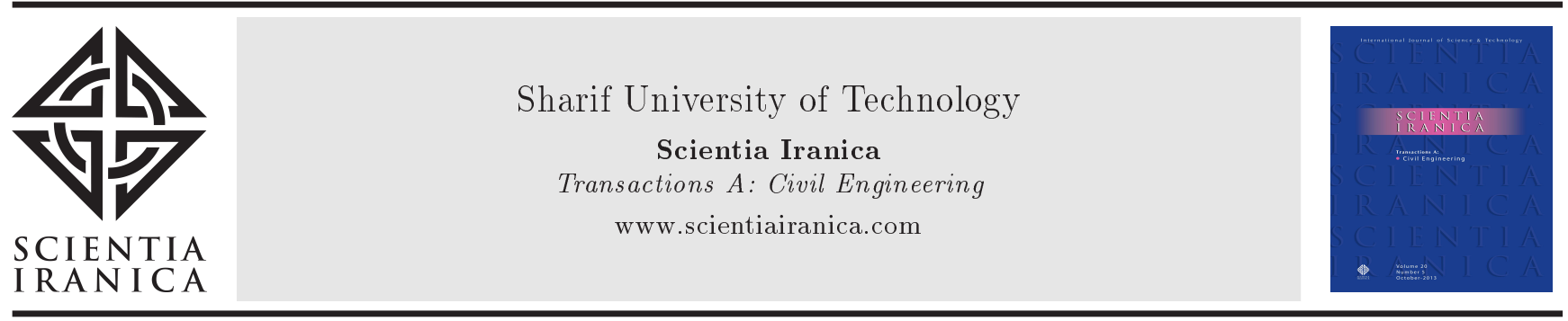

Research Note

\title{
Assessment of change in acoustic wave velocity of compacted expansive soil through experiments
}

\author{
B.X. Wei* and Z. Huang \\ School of Highway Engineering, ChangSha University of Science and Technology, Wanjiali South Road 960, Changsha, Hunan \\ 410004, China.
}

Received 17 October 2014; received in revised form 4 May 2015; accepted 19 December 2016

\author{
KEYWORDS \\ Compacted expansive \\ soil; \\ P-wave velocity; \\ Drying-wetting cycles; \\ Cyclic amplitude; \\ Constant amplitude.
}

\begin{abstract}
In the present study, the non-metal acoustic wave monitor, TH204, has been used to determine P-wave velocity of compacted expansive soil under the condition of drying-wetting cycles with constant amplitude to explore the change in P-wave velocity of compacted expansive soil with the cyclic number, cyclic amplitude and control moisture content. The results show that the P-wave velocity of the compacted expansive soil follows a non-linear decrease rate with increasing the cyclic number, while it tends to be stable. Also, under the conditions of equivalent control moisture rate and cyclic number, the cyclic amplitude has great effect on the P-wave velocity of expansive soil. Thus, with increase in the cyclic amplitude, the P-wave velocity decrease. Secondly, under the same cyclic number, the $\mathrm{P}$-wave velocity changes with the control moisture rate monotonously. Further, the study shows that the peak values of $\mathrm{P}$-wave velocity appear near the optimum moisture rate, and the peak value position remains unaltered with change of cyclic amplitude.
\end{abstract}

(C) 2017 Sharif University of Technology. All rights reserved.

\section{Introduction}

The acoustic measurement, which is used for mechanical properties of rocks in comparison with static method, is a non-destructive, simple, rapid, reliable, and economical method, and it has been widely applied to rock engineering. Many domestic and foreign studies are available which describe the acoustic characteristics of rocks. Ultrasonic non-destructive evaluation method was previously presented by Lachouri et al. in 2004 [1] and Saad et al. in 1999 [2]. Zhou et al. [3] studied the frequency spectrum characters of acoustic wave of a tunnel wall rock. The results show that the frequency spectrum reflects the characters of structure, formation, and integrality of wall rock to a certain degree. Zhao et al. [4] studied rock mass classification by a

*. Corresponding author. Tel: $0086+18684907814$ E-mail addresses: weibingxu555@163.com (B.X. Wei); hzcslg@163.com (Z. Huang) combination of the RMR (Rock Mass Rating) and Qsystem (the Q-system for the rock mass classification), which is related to ultrasonic velocity based on the foregoing investigations, empirical formula, and rock mass strength prediction by the existing relationship between the RMR and Hoek-Brown criteria. The correlation between ultrasonic velocity and physical and mechanical properties of rock was studied by Pan et al. in 2010 [5], Chai et al. in 1985 [6], and Wang et al. in 2011 [7]. These authors argue that the ultrasonic velocity varies with physical and mechanical properties of rock and has a functional relationship.

The theoretical research on the ultrasonic characteristics and their association with mechanical parameters of the soil is still in earlier stages, and none of the studies is available in the correlated research. Also, some of the studies carried out in China have focused only on ultrasonic characteristics of freezing soil and loess. Wang et al. [8] tested the sonic velocity of disturbed and undisturbed loesses and provided an 
empirical formula for ultrasonic velocity and physic mechanical appearance of loess. The authors proved that the method of investigating rock mass properties by ultrasonic velocity is feasible in soil mass. Wang et al. [9] calculated the dynamic elastic mechanical parameters of the tested frozen soil based on the elastic theory in terms of the measured ultrasonic wave velocities in frozen fine sand, silt(loess), and clay. In another study, the influence of moisture rate and temperature below $0^{\circ}$ centigrade on the propagation of ultrasonic waves in the frozen soil was studied, and the dynamic elastic mechanical indexes of the frozen soil based on the measured results of ultrasonic velocity in frozen Harbin silty in China were also discussed [10].

However, the correlation study of the acoustic characteristics of expansive soil, such as wave velocity, wave forms, wave frequency spectrum, etc., has not yet been reported. Therefore, in this paper, based on ultrasonic wave testing technique, $\mathrm{P}$-wave velocity of compacted expansive soil has been determined under the condition of drying-wetting cycles with constant amplitude through the non-metal acoustic wave monitor. Analyzing the variation of $\mathrm{P}$-wave velocity with cyclic number, cyclic amplitude and control moisture rate, empirical formula of variation of wave velocity with drying-wetting number is established. Also, the research results can provide a theoretical basis for studying ultrasonic theory and acoustic characteristics of soil.

\section{Basic theory of ultrasonic test}

The ultrasonic velocity of rock is related to elastic medium and internal structure of rock [11], which is the theoretical basis of ultrasonic test of compacted expansive soil. For specimens with the materials of the same composition, the internal structure is complete, with the development degree of fissure being lower and ultrasonic velocities being higher.

Expansive soil is a special unsaturated soil. Under drying-wetting cycles, lots of fissures can be generated, bringing about an increase and growth in intrinsic structure of soil mass. When acoustic wave travels through fissured expansive soil, it can reflex, refract, and diffract at the edge of fissure, which results in elongation of acoustic wave propagation path. Hence, the sonic time of fissured specimen is longer than that

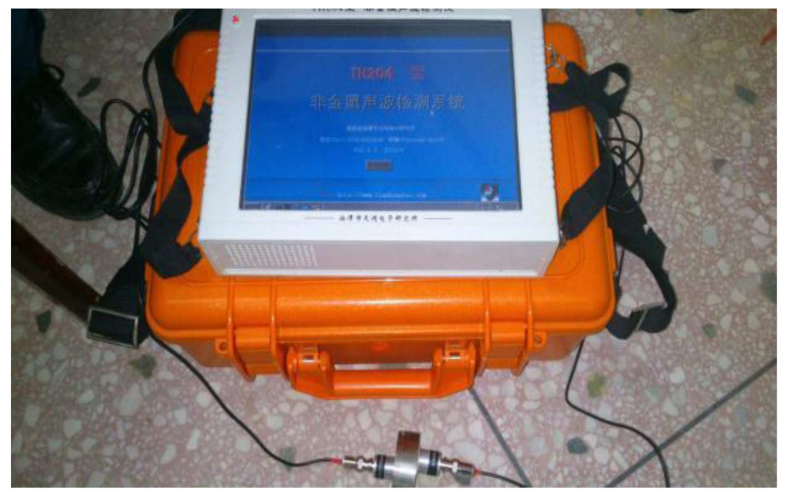

Figure 1. The acoustic waves monitor.

of the undamaged specimen. Thus, the sonic wave velocity of fissured specimen is lower than undamaged in expansive soil specimen. The commercial non-metal acoustic wave monitor, TH204, is shown in Figure 1.

\section{Test process}

The soil was sampled at depth of $1.5 \mathrm{~m}-2.0 \mathrm{~m}$ below the earth's surface from Baise basin, a typical expansive soil area in China. The soil samples which inherently have moisture rate varying from $15 \%$ to $23 \%$ are grey in color. The basic physical indices of expansive soil are given in Table 1. The samples were dried, crushed, and passed through $2 \mathrm{~mm}$ sieves. The initial moisture rate of samples was set at $W=15 \%, 17 \%, 19 \%, 21 \%$, and the samples were sealed over $24 \mathrm{~h}$ to uniform the moisture rate of the samples. The specimens with 1.7 $\pm 0.02 \mathrm{~g} / \mathrm{cm}^{3}$ of dry density, $61.9 \mathrm{~mm}$ in diameter, and $20 \mathrm{~mm}$ in height were prepared by static-load way, and six drying-wetting cycles were simulated with: $\Delta W=$ $\pm(10 \pm 0.1) \%, \pm(7.5 \pm 0.1) \%, \pm(5 \pm 0.1) \%$, and $\pm(2.5 \pm$ $0.1) \%$ of cyclic amplitudes, respectively.

Since the temperature in Baise area in China can reach $40^{\circ} \mathrm{C}$ in summer, dewatering was conducted for specimens at $40^{\circ} \mathrm{C}$ in this test to control moisture rate. Precipitation was simulated by sprinkling with subminiature atomizer. The weight control method was used to control moisture rate of samples in this study. When the corresponding control moisture rate was reached, the samples were sealed over $24 \mathrm{~h}$ to unify internal and external moisture rates of samples. During the course of the process of drying-wetting cycles, the control moisture rate is equal to initial moisture content.

Table 1. Basic physical indexes of expansive soil.

\begin{tabular}{|c|c|c|c|c|c|c|c|c|}
\hline \multirow[t]{2}{*}{$\begin{array}{c}\text { Bulk } \\
\text { density } \\
(\text { g.cm } \\
-3\end{array}$} & \multirow[t]{2}{*}{$\begin{array}{c}\text { Liquid } \\
\text { limit } \\
(\%)\end{array}$} & \multirow[t]{2}{*}{$\begin{array}{l}\text { Plasticity } \\
\text { index }\end{array}$} & \multirow[t]{2}{*}{$\begin{array}{c}\text { Optimum } \\
\text { water rate } \\
(\%)\end{array}$} & \multirow[t]{2}{*}{$\begin{array}{l}\text { Maximum } \\
\text { dry density } \\
\left(\mathrm{g} . \mathrm{cm}^{-3}\right)\end{array}$} & \multicolumn{3}{|c|}{$\begin{array}{c}\text { Particle } \\
\text { composition (\%) }\end{array}$} & \multirow[t]{2}{*}{$\begin{array}{l}\text { Free swelling } \\
\text { ratio }(\%)\end{array}$} \\
\hline & & & & & $>0.075 \mathrm{~mm}$ & $0.075-0.005 \mathrm{~mm}$ & $<0.005 \mathrm{~mm}$ & \\
\hline 2.092 & 56.26 & 34.89 & 17.46 & 1.80 & 0.1 & 52.02 & 47.88 & 82 \\
\hline
\end{tabular}


Since the saturated moisture rate of samples is $29 \%$, moistening $10 \%$ of moisture rate cannot be realized in the test process for $21 \%$ of initial moisture rate. In other words, The samples with $21 \%$ of initial moisture rate have 3 kinds of cyclic amplitudes, others have 4 kinds of cyclic amplitudes. Therefore, in this study, 60 samples were divided into 15 groups with 4 samples in each group.

The $\mathrm{P}$-wave velocity of samples with the same initial moisture rate, which experienced the same cyclic number and the same cyclic amplitude, was measured using commercial, non-metal acoustic wave monitor whose transducers' frequency is $500 \mathrm{kHz}$, and sample interval is $0.5 \mu \mathrm{m}$ with Vaseline as couplant. The acoustic velocity was measured for 2-3 cross-sections for each of the samples, and the outliers were identified using the limiting error method, i.e., the outlier data are deleted and substituted with arithmetic average value when the measurement error is 3 times larger than the standard error, and the mean velocity value was taken as the acoustic velocity of each sample. Also, the average acoustic velocity should be used as the representative value of each group of samples.

\section{Results and discussion}

\subsection{Variation of average P-wave velocity with the number of drying-wetting cycles}

The average $\mathrm{P}$-wave velocity has a nonlinear decrease relationship under the same control moisture rate and cyclic amplitude while increasing the number of dryingwetting cycles. This non-linear relationship between the average $\mathrm{P}$-wave velocity of expansive soil specimens and the number of drying-wetting cycles was fitted by cubic polynomial curve, as shown in Figures 2-5. The non-linear empirical formula of average $\mathrm{P}$-wave velocity decrease was obtained by regression Eq. (1):

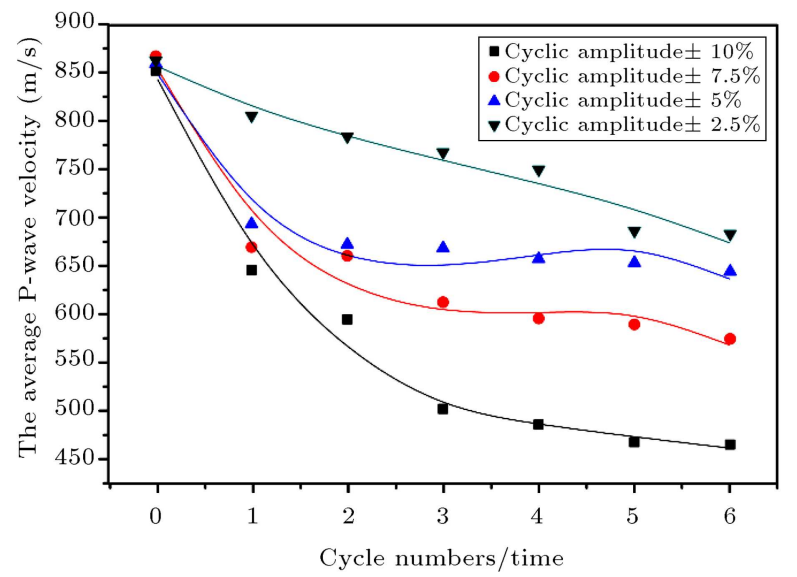

Figure 2. Variation of average $\mathrm{P}$-wave velocity with the number of drying-wetting cycles (control moisture rate is $15 \%)$.

$$
V_{P}=A N^{3}+B N^{2}+C N+D \quad(1 \leq N \leq 6),
$$

where $V_{P}$ is the average $\mathrm{P}$-wave velocity of expansive soil; $N$ is the number of drying-wetting cycle;

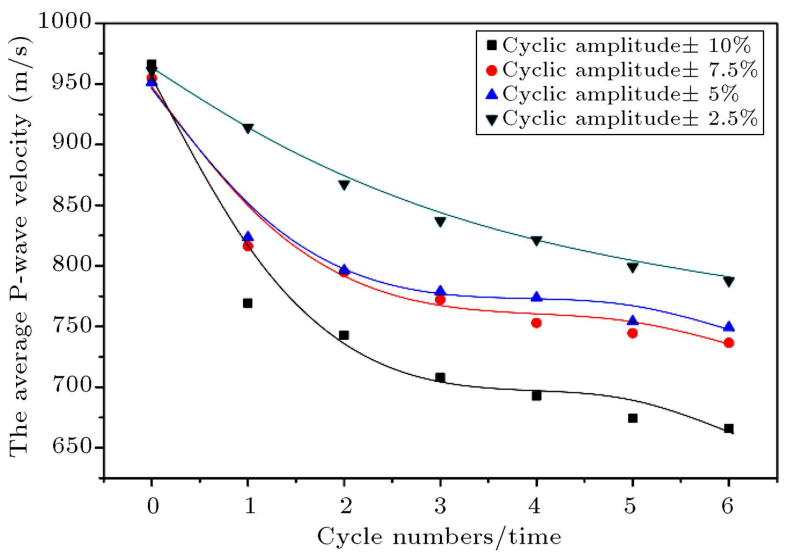

Figure 3. Variation of average P-wave velocity with the number of drying-wetting cycles (control moisture rate is $17 \%)$.

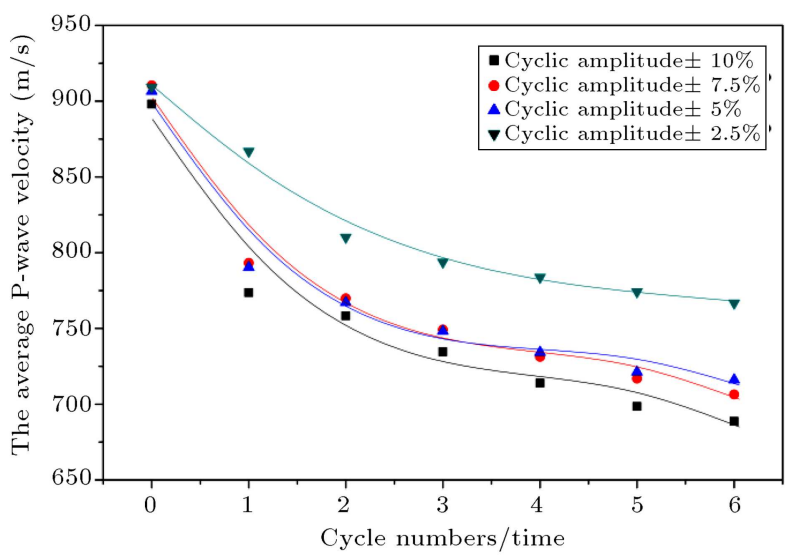

Figure 4. Variation of average P-wave velocity with the number of drying-wetting cycles (control moisture rate is $19 \%)$.

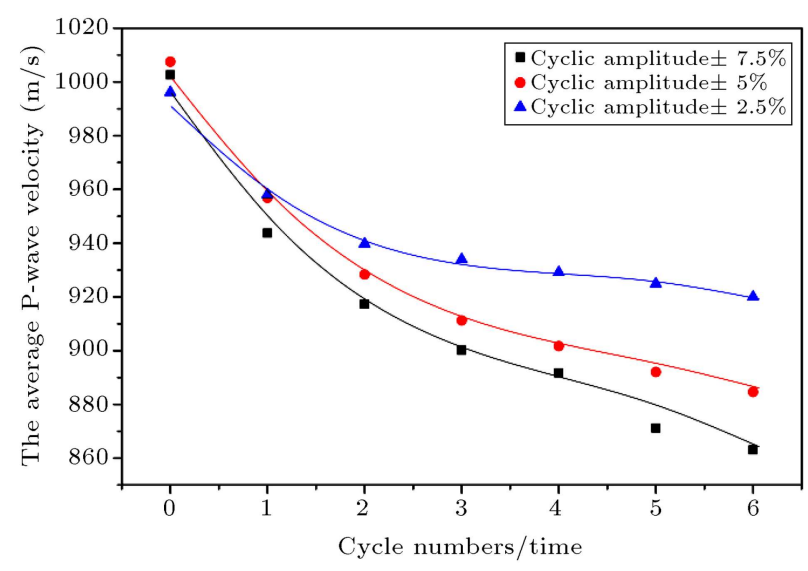

Figure 5. Variation of average P-wave velocity with the number of drying-wetting cycles (control moisture rate is $21 \%)$. 
Table 2. Correlation coefficients of polynomial fitting.

\begin{tabular}{clccccc}
\hline $\begin{array}{c}\text { Control moisture } \\
\text { rate (\%) }\end{array}$ & $\begin{array}{c}\text { Cyclic } \\
\text { amplitude }(\%)\end{array}$ & \multicolumn{3}{c}{ Constant } & & $\begin{array}{c}\text { Correlation } \\
\text { coefficient }\end{array}$ \\
\cline { 3 - 6 } & & $\boldsymbol{A}$ & $\boldsymbol{B}$ & $\boldsymbol{C}$ & $\boldsymbol{D}$ & $\boldsymbol{R}^{\mathbf{2}}$ \\
\hline \multirow{2}{*}{$15 \%$} & $\pm 2.5 \%$ & -0.7206 & 7.1624 & -47.451 & 857.11 & 0.9604 \\
& $\pm 5 \%$ & -4.4450 & 50.186 & -176.420 & 849.17 & 0.9597 \\
& $\pm 7.5 \%$ & -4.1072 & 48.744 & -192.180 & 854.17 & 0.9580 \\
& $\pm 10 \%$ & -2.7769 & 40.908 & -209.080 & 843.48 & 0.9858 \\
\hline \multirow{2}{*}{$17 \%$} & $\pm 2.5 \%$ & -0.3472 & 7.0218 & -58.719 & 962.18 & 0.9979 \\
& $\pm 5 \%$ & -3.0656 & 35.675 & -137.260 & 944.95 & 0.9776 \\
& $\pm 7.5 \%$ & -2.9064 & 34.780 & -139.870 & 946.57 & 0.9724 \\
& $\pm 10 \%$ & -4.3097 & 50.952 & -199.930 & 954.48 & 0.9701 \\
\hline \multirow{2}{*}{$19 \%$} & $\pm 2.5 \%$ & -0.6506 & 10.891 & -66.066 & 912.54 & 0.9883 \\
& $\pm 5 \%$ & -2.4594 & 29.479 & -119.760 & 900.13 & 0.9776 \\
& $\pm 7.5 \%$ & -2.4747 & 29.233 & -119.950 & 903.95 & 0.9792 \\
& $\pm 10 \%$ & -2.4997 & 29.385 & -120.710 & 889.84 & 0.9686 \\
\hline & $\pm 2.5 \%$ & -0.8972 & 10.913 & -45.878 & 995.41 & 0.9972 \\
& $\pm 5 \%$ & -0.8736 & 11.741 & -59.485 & 1006.90 & 0.9994 \\
& $\pm 7.5 \%$ & -1.1511 & 13.943 & -65.567 & 1000.80 & 0.9937 \\
\hline
\end{tabular}

$A, B, C$, and $D$ are coefficients related to control moisture rate, cyclic amplitude, and other factors, respectively.

Table 2 presents regression coefficients $A, B, C$, and $D$ and correlation coefficient $R^{2}\left(R^{2} \geq 0.9580\right)$. It can also be seen from Figures 2-5 that the average Pwave velocity decreases with increasing cyclic number and tends to be stable under the condition of the same control moisture rate and the same cyclic amplitude. Since the average $\mathrm{P}$-wave velocity is related to the degree of development of fissures, the curves in Figures 25 can be divided into 3 stages. The first stage is a rapid decline stage of ultrasonic velocity from zero to 2 nd cycle; the second stage is the slow decline stage from 3 rd to 5 th cycle; the third stage tends to be a stable one in the 6 th cycle $[12,13]$. The fissures of the expansive soil under zero to 2 nd drying-wetting cycle are fine with smaller fissure rate. The first drying-wetting cycle can greatly increase the fissure rate, the width, and depth of the fissures of the expansive soil. Thus, the increase in fissure rate results in decrease of the average $\mathrm{P}$-wave velocity. However, the effects of the 3 rd to 6 th dryingwetting cycles on the fissure rates gradually decrease, allowing the wave velocity to stabilize.

\subsection{Variation of the average P-wave velocity with increasing cyclic amplitude}

The variation of average $\mathrm{P}$-wave velocity of expansive soil with cyclic amplitude is shown in Figures 69. Figures 6-9 show that the $\mathrm{P}$-wave velocity with zero drying-wetting cycle is approximately linear under the condition of the same control moisture rate and cyclic amplitude. Secondly, under the same number of drying-wetting cycles, P-wave velocity decreases with the increase of cyclic amplitude. It could be attributed to the reason that the surface of the sample directly comes in contact with warm air during dewatering, and the internal and external sections of sample have nonuniform distribution of dewatering rate with the rate being higher in outside than inside. Thus, the moisture rate gradient is obtained, which causes stress in the samples. Hence, as the cyclic amplitude increases, there will be a greater moisture rate gradient between the internal and external sections of sample, and more stress is made on the sample, causing fissure formation easier. Furthermore, under the same control moisture rate and the number of drying-wetting cycle,

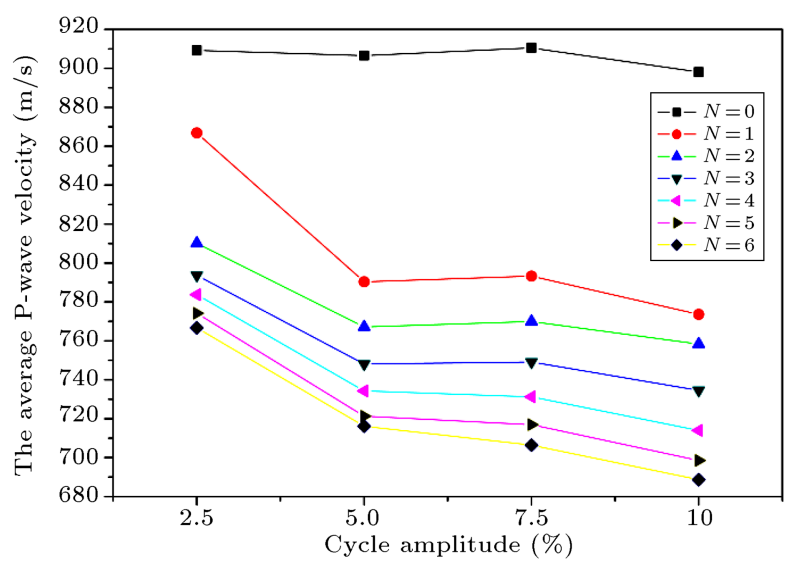

Figure 6. Variation of the average P-wave velocity with cyclic amplitude (initial moisture rate is 15\%). 
more amount of time is required for dewatering with increasing cyclic amplitude. Thus, with longer timeeffect, prolonged tension is produced by moisture rate gradient, and that results in generation of greater number of fissures and lowering of the P-wave velocity.

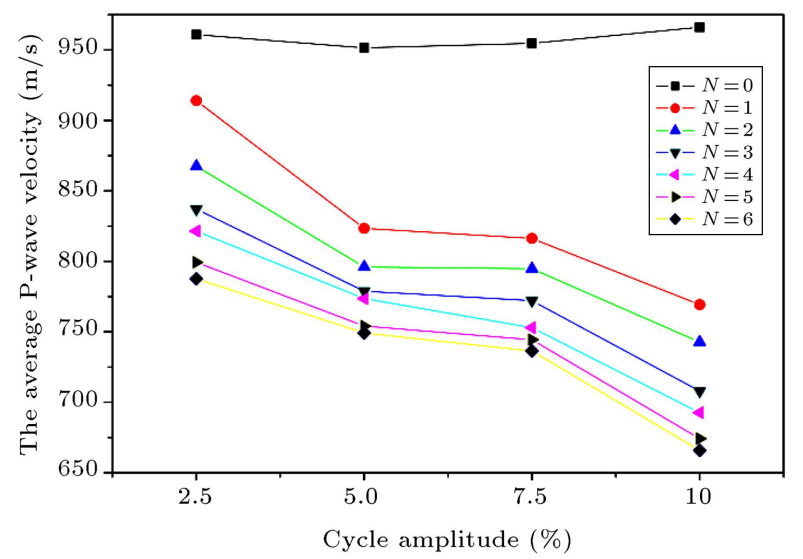

Figure 7. Variation of the average P-wave velocity with cyclic amplitude (initial moisture rate is $17 \%$ ).

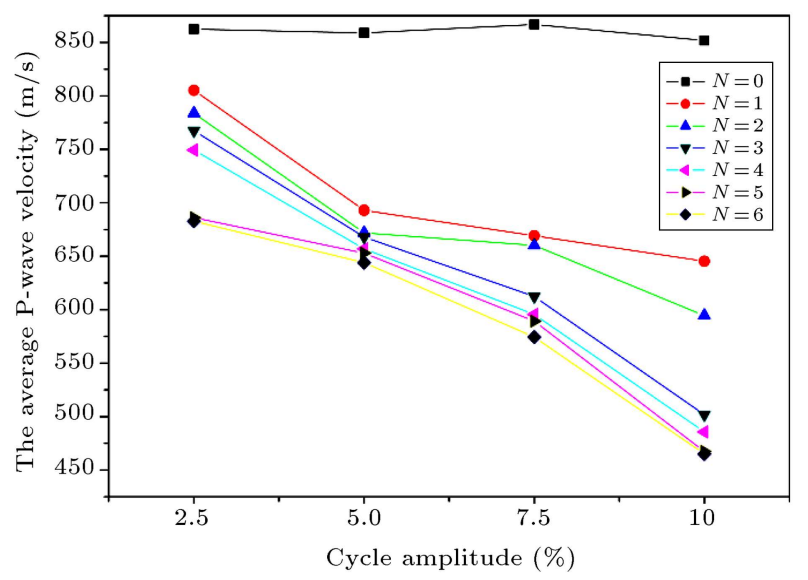

Figure 8. Variation of the average P-wave velocity with cyclic amplitude (initial moisture rate is $19 \%$ ).

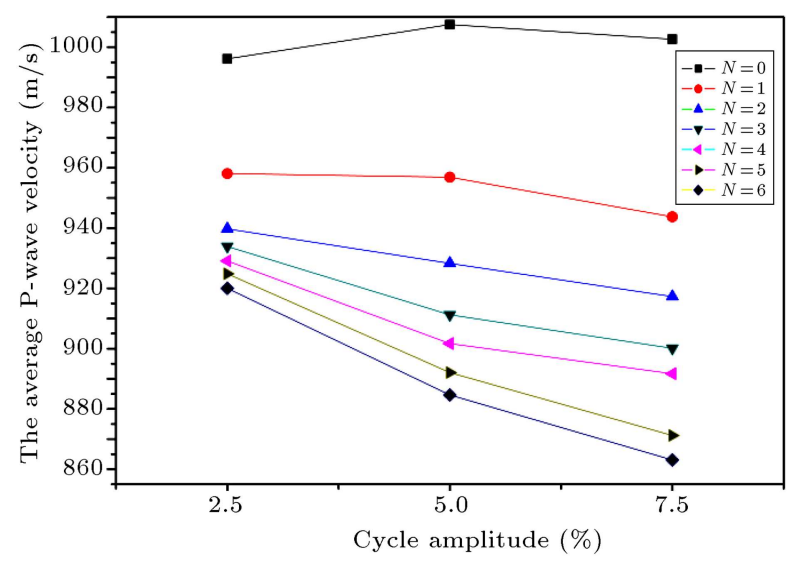

Figure 9. Variation of the average P-wave velocity with cyclic amplitude (initial moisture rate is $21 \%$ ).

\subsection{Variation of the P-wave velocity with the control moisture rate}

Change in moisture rate of rock and soil mass causes change in the wave velocity. Figures 10-16 present the variation of the average $\mathrm{P}$-wave velocity with control moisture rate. The figures show that under the same cyclic amplitude and the same number of drying-wetting cycle, the relationship between $\mathrm{P}$-wave velocity and control moisture rate is obviously nonlinear and non-monotonic. Other studies have come up with similar findings $[14,15]$. It can be observed from the figures that the position of peak value of $\mathrm{P}$ wave velocity remains unaltered with the change in cyclic amplitude. Since the relationship between Pwave velocity and moisture rate is complex, further research is needed.

\section{Conclusions}

The decrease formula of $\mathrm{P}$-wave velocity of the compacted expansive soil with increasing cyclic number, presented in this paper, can be used to calculate sonic

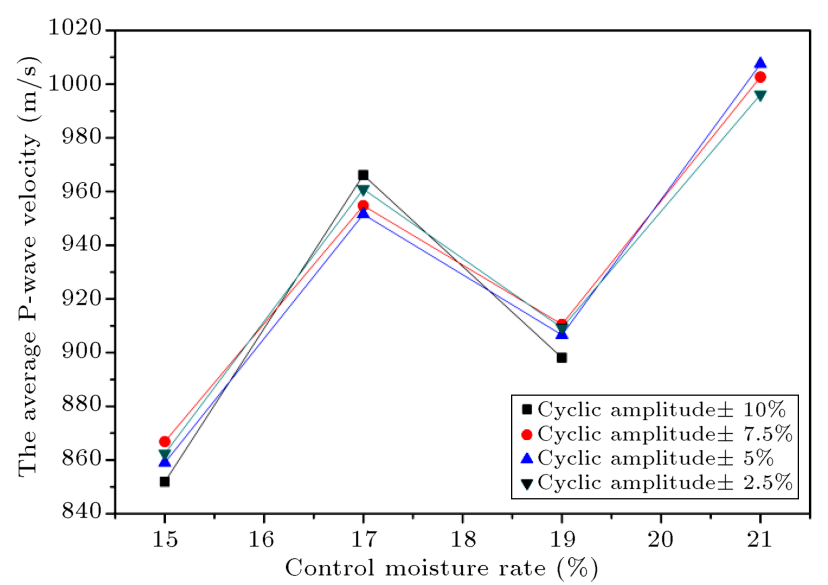

Figure 10. Variation of the average $\mathrm{P}$-wave velocity with initial water content $(N=0)$.

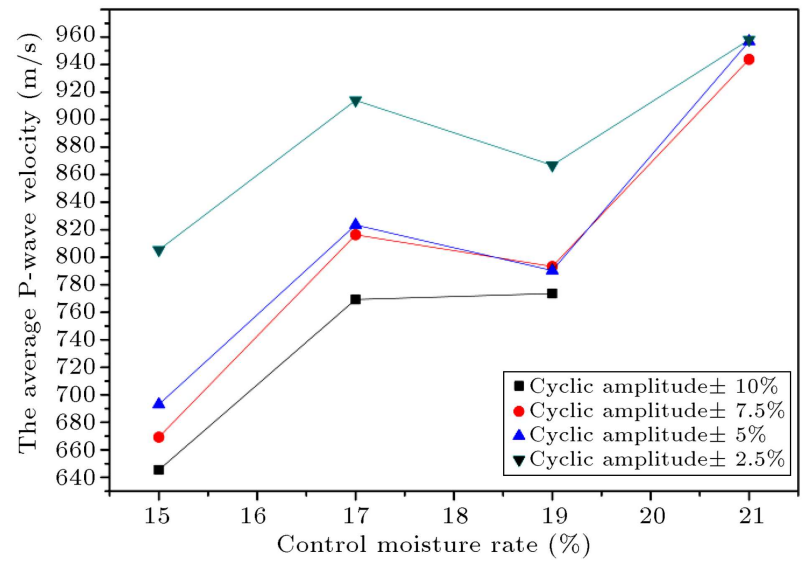

Figure 11. Variation of the average $\mathrm{P}$-wave velocity with initial water content $(N=1)$. 


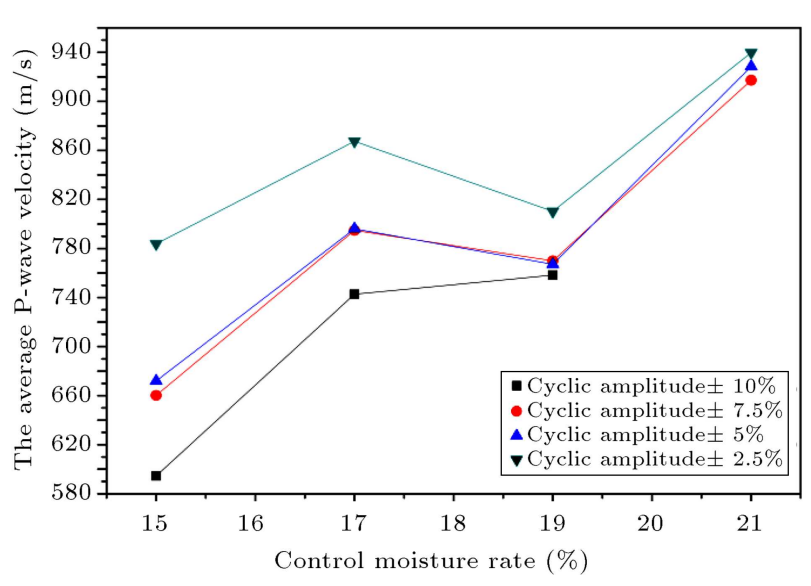

Figure 12. Variation of the average $\mathrm{P}$-wave velocity with initial water content $(N=2)$.

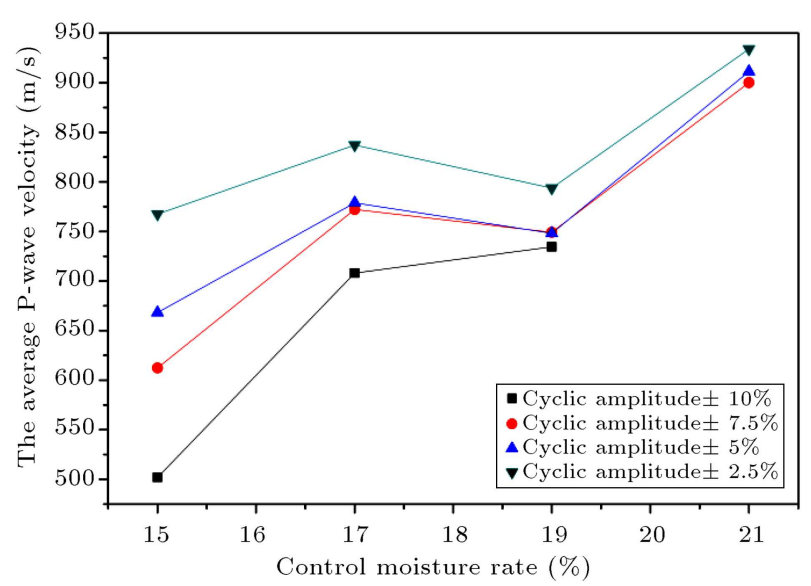

Figure 13. Variation of the average P-wave velocity with initial water content $(N=3)$.

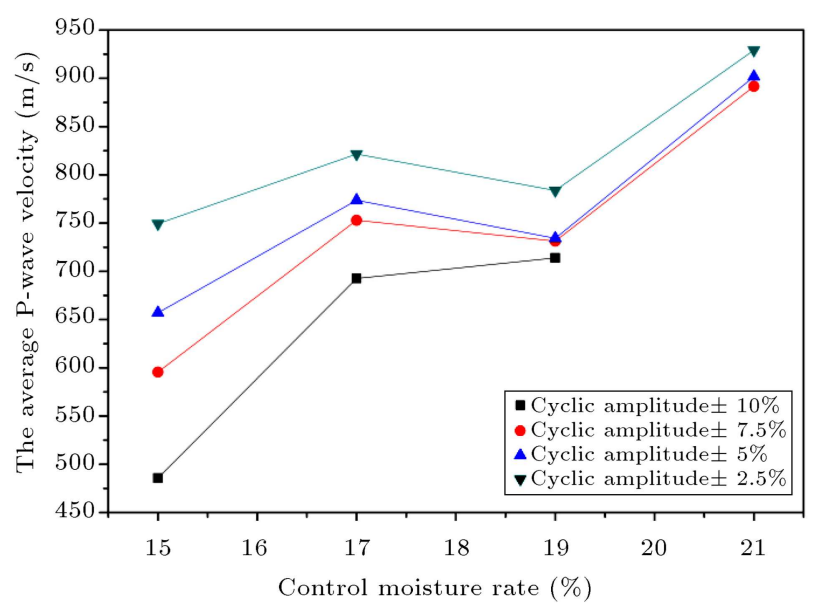

Figure 14. Variation of the average P-wave velocity with initial water content $(N=4)$.

wave velocity of expansive soil in Baise region under drying-wetting cycles. The present study favors the application of non-destructive testing technique for the expansive soil. The study shows that the $\mathrm{P}$-wave

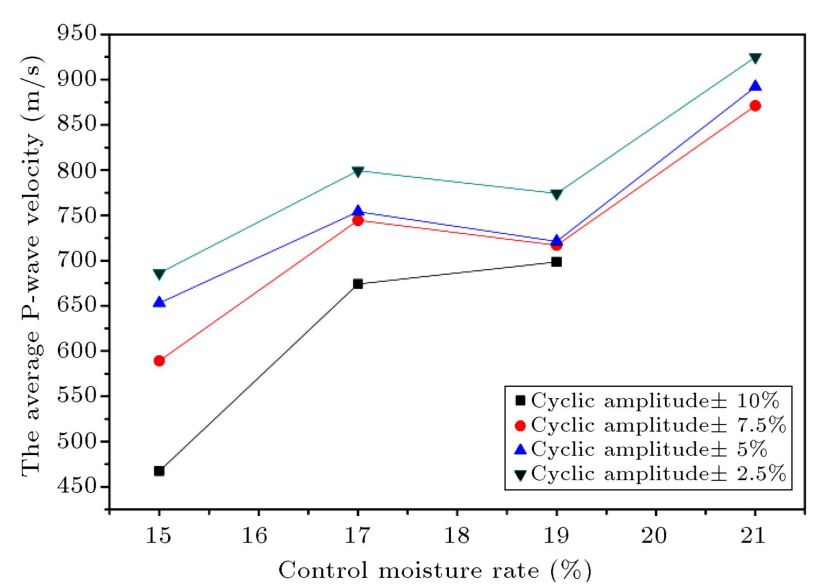

Figure 15. Variation of the average P-wave velocity with initial water content $(N=5)$.

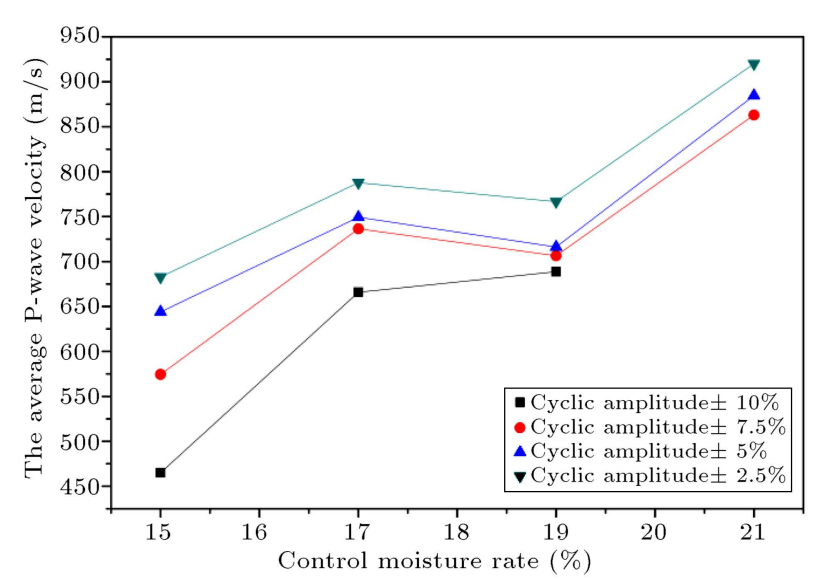

Figure 16. Variation of the average P-wave velocity with initial water content $(N=6)$.

velocity of expansive soil is related not only to cyclic amplitude and the number of drying-wetting cycles, but also to the control moisture rate. Thus, there is also a need for further studies which understand other factors, such as compaction degree and cycle period, affecting the $\mathrm{P}$-wave velocity of the expansive soil.

\section{References}

1. Lachouri, A., Doghmane, N. and Benouareth, M. "Study of rock acoustic characteristics by parametric spectra analysis", Information and Communication Technologies: From Theory to Applications, pp. 387388 (2004).

2. Saad, S., Herous, L., Doghmane, N. and Lachouri, A. "Laboratory study of rock acoustic characteristics by parametric spectral estimation", Acta Geodaetica et Geophysica Hungarica, 34(1-2), pp. 101-110 (2013).

3. Zhou, B.R., Jian, W.B., Chen, X.Z. and Li, K. "Exploration for acoustic characteristics of rock mass in a tunnel project", Journal of Water Resources Architectural Engineering, 10(3), pp. 25-29 (2012). 
4. Zhao, M.J. and Wu, D.L. "The ultrasonic identification of rock mass classification and rock mass strength prediction", Chinese Journal of Rock Mechanics and Engineering, 19(1), pp. 89-92 (2000).

5. Pan, J.W. and Su, C.D. "Study on relation among strength, average moduli and longitudinal wave velocities for sandstone", Journal of Mining \& Safety Engineering, 27(1), pp. 24-29 (2010).

6. Chai, Z.L., Liu, K. and Huang, J.Y. "The study of relation between ultrasonic waves frequency spectral properties and mechanical properties of rock", Chinese Journal of Geotechnical Engineering, 7(6), pp. 1-6 (1985).

7. Wang, Z.J. "Research on macro-scopical quantitative relation between wave velocity and strength of rock (rock mass)", Journal of Railway Engineering Society, 10, pp. 6-9 (2011).

8. Wang, Z.H., Testing Study on Relationship Among $P$-Wave Velocity and Physico-Mechanical in Xiashu Loess, NanJing, Hohai University (2007).

9. Wang, D.Y., Zhu, Y.L., Yuan, L., Zhao, S.P. and Li, H.P. "Study on experimental determination of the dynamic elastic mechanical parameters of frozen soil by ultrasonic technique", Chinese Journal of Geotechnical Engineering, 24(5), pp. 612-615 (2002).

10. Ling, X.Z., Xu, X.Y., Xu, C.H. and Li, X.Z. "Study on frozen Harbin sillty clay through its measuring tests of ultrasonic velocity", Chinese Journal of Geotechnical Engineering, 24(4), pp. 456-459 (2002).

11. Fan, X.F., Wu, Z.X. and Jian, W.B. "Analysis of acoustic property of sandstone fatigue damage under cyclic loading", Rock and Soil Mechanics, 30(supp.), pp. 58-62 (2009).

12. Yang, H.P., Liu, Y.Q. and Li, H.F. "The development of cracks of compacted expansive soil under dry-wet cycling", Journal of Transport Science and Engineering, 28(1), pp. 1-5 (2012).
13. Lü, H.B., Zeng, Z.t. and Zhao, Y.L. "Preliminary study on accumulative damage of expansive soil in alternation of wetting-drying environment", Journal of Natural Disasters, 21(6), pp. 119-123 (2012).

14. Deng, H.F., Yuan, X.F. and Li, J.L. "Experimental research on influence of saturation degree on sandstone longitudinal wave velocity and strength", Chinese Journal of Rock Mechanics and Engineering, 32(8), pp. 1625-1631 (2013).

15. Pan, D.Q., Zhang, Z.P. and Pan, D.C. "A test research on longitudinal wave velocity of artificial frozen clay under different temperature and moisture conditions", Journal of Jilin University (Earth Science Edition), 36(4), pp. 588-591 (2006).

\section{Biographies}

Bing Xu Wei is a Professor at the Department of traffic and Transportation Engineering and a Researcher in Changsha University of Science and Technology, Changsha, China. He received his $\mathrm{PhD}$ degree from Northeastern University in China. He was one of the first prize winners of the national science and technology progress in China (2008). He has more than 50 publications in journals. His research interests include geotechnical engineering, tunnel engineering, slope reinforcement, and protection design.

Zhen Huang is a doctoral student in the School of Civil Engineering, Central South University. He received a master's degree from Changsha University of Science and Technology in 2011. He has participated in a number of National Natural Science Foundation of China. He has more than 20 publications in journals. His research interests include special soil engineering, rock engineering, slope stability analysis, safety risk analysis of tunnel structure. 